\title{
Fishkin, Joseph (2014). Bottlenecks. A New Theory of Equal Opportunity. Oxford, New York: Oxford University Press, 267 p., ISBN 9780199812141.
}

Reviewed by DARKo ŠTrAJN ${ }^{1}$

What immediately catches the reader's attention in this book is a proposition in which the author affirms the idea of opportunity pluralism. In Fishkin's words, this idea brings a "shift in focus" from questioning "whose opportunities are equal or unequal" to a more "structural way", (p. 1) that incorporates the creation, distribution and control of opportunities. He goes on to describe the multiplicity of ways in which people think about equality of opportunity, indicating categories and concepts such as class, gender, the family and so forth, on the one hand, and the different structuring of opportunities in various societies,

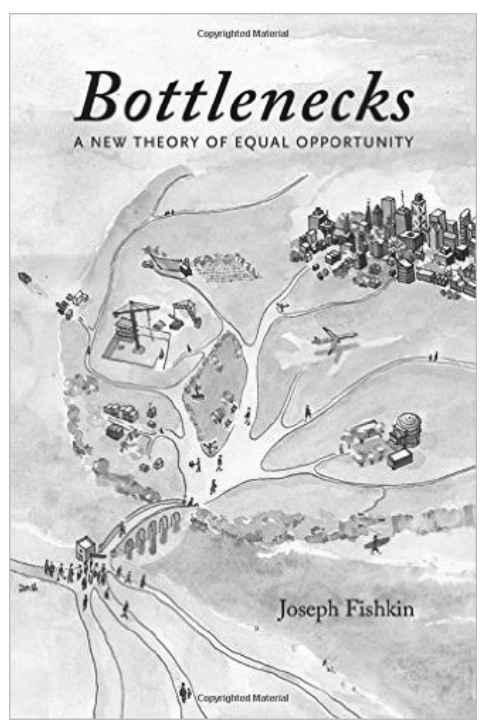
on the other. In the introductory part, the author claims that his book is "about the ways societies should, and do, structure opportunities" (p. 10). He then gives a rather well-chosen example from Bernard Williams regarding the "warrior society", in which the state hypothetically introduces equality of opportunity by also allowing children of "non-warriors" to participate in the competition for the limited number of military jobs; however, this has little impact on the outcome, as warriors' children come to the competition much better prepared. Although the example is unrealistic, "different modern societies resemble the warrior society to a greater or a lesser degree" (p. 13). The concluding part of the Introduction reminds the reader that racial discrimination, health disparities, the gender-role system and other such phenomena create bottlenecks. "But so too can certain testing regimes, credential requirements, forms of economic organization, oppressively conformist social norms, and many other stones that our usual ways of approaching equal opportunity might leave unturned" (p. 18).

1 Educational Research Institut, Ljubljana, Slovenia. 
The first chapter of Fishkin's book addresses, above all, the conception of fair contest, and proceeds by discussing the theories of thinkers such as Rawls and Dworkin, to mention just the most outstanding names. This very detailed examination of different arguments, concepts and antagonisms is interwoven with a wide range of problems linked to the family, nature, education, merit, jobs, the starting gate, etc. Many representative and evocative examples are given, as is typical of a kind of thinking based on the paradigm of analytical philosophy. In view of this line of thinking, Fishkin finds "Nozick's vision of radically decentralized pluralism / .../ too unrealistic" (p. 77), and therefore advocates a "different kind of equal opportunity".

The second chapter examines relations between opportunities and human development: "/.../ this chapter explains why we ought to be concerned not just about who has more opportunities and who has less, but also about which opportunities or what kinds of opportunities are open to people" (p. 83). The author presents a variety of theories and misconceptions (such as those based in genetic science, environmental studies, chance, etc.) and, of course, does not omit a discussion of the notorious difference between nature and nurture. In this context, he mentions the "Flynn Effect", which makes linking everhigher IQ to genetics very problematic. However, he also very persuasively does away with "oversimplifications" in views on the "intergenerational transmission of inequality" (p. 108). In the same chapter, Fishkin also tackles complex problems concerning interactions with the world of employment, questioning the notion of merit, but also exposing some mindboggling problems with the ideas of equality and equalising. The problems become clearly comprehensible as challenges when we see them through the author's interpretation of wellchosen examples from social situations and courtrooms. School as an "equaliser" is one of the important matters of discussion in this chapter, and practices such as testing are thoroughly examined and exposed as problematic.

The third chapter is about "opportunity pluralism". This consists of "four principles", which are here only briefly summarised from pages 131-132: (1) there should be plurality of values and goals in society, (2) valued goods should not be "positional" and as many roles as possible should not be competitive, (3) the "anti-bottleneck principle" supports plurality of paths to different valued goods and roles, and (4) "plurality of sources of authorities" translates to "broader plurality of different decision-makers". In the continuation, these principles are well substantiated and discussed with reference to various theories, going as far back as J. S. Mill. Some realistic examples, based on verifiable evidence, again provide good backing for the author's theses. This chapter is the highpoint of the whole book, as it suggests what the idea of opportunity pluralism is about. 
One contribution of particular interest is the argumentation against harsh competitiveness, although the author himself believes that many instances of such competitiveness will never disappear.

In the chapter entitled "Applications", the author examines matters of economic and social policy "through the lens of opportunity pluralism". After explaining how many "interconnected" bottlenecks add up to a "major class bottleneck", he focuses on problems of work flexibility and, finally, "discusses how the anti-bottleneck principle should recast our understanding of antidiscrimination law" (p. 198).

The Conclusion takes a stand against the zero-sum outcome, claiming that according to opportunity pluralism there can be a "positive-sum". Due to its original propositions, the book should be included among theoretical resources in any serious attempt to reform the area of the creation of "equal opportunities". Of course, this holds true for a kind of moderately leftist liberal social reform, as the author notably links opportunity and individual freedom. One can only hope that this book will have some impact, as it is one of a number of recent studies that deal with concerns about growing income inequalities and the consequent broader social imbalances.

The author is mainly focused on problems in the United States, and the bulk of examples and other evidence come from that environment, although in some instances he compares American systems and policies to those of Europe. As mentioned above, the book is based on an analytical philosophical paradigm and therefore disregards concepts, logics and critique based on the so-called continental paradigm. Hence, Fishikin entirely overlooks such highly valued contributions as, for instance, Pierre Bourdieu's study of the reproduction of a society (through education) and particular aspects of Michel Foucault's work on the problems of power relations, as well as some more contemporary approaches to sociology, such as Ulrich Beck's or Christian Laval's critical reflections on the neoliberal form of capitalism and its effects in a range of social institutions. In the case of Fishkin's book, however, this is not necessarily a weakness; firstly because the book retains a firm consistency due to the "logic" on which it is grounded, and secondly because it demonstrates the power of an analytical methodology, which makes particular social situations, the legal system, individual institutions, a range of practices in a multitude of policies, and social controversies and conflicts better visible in their detail. Such approaches also generate a degree of "rationality" in public discourse, and therefore may better serve social or political reform in a given legal framework than their "continental" counterparts. However, these approaches cannot develop a fundamental criticism, which remains the advantage of discourses rooted in a more "holistic" approaches, discourses that are mainly characteristic of European humanities and social sciences. 